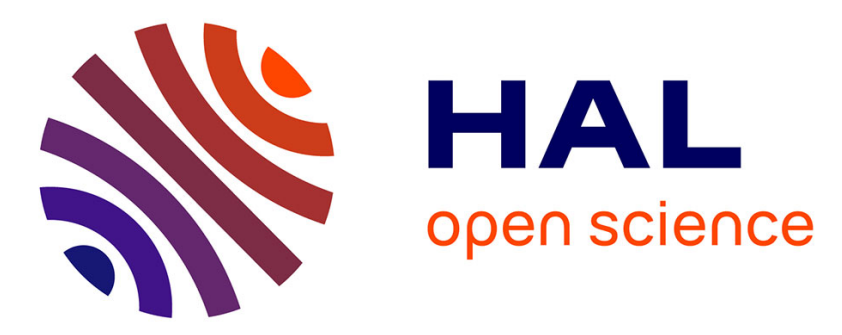

\title{
L'ARN satellite du virus de la mosaïque du concombre. III. - La propriété de survie in vivo
}

Mireille Jacquemond, Hervé Lot

\section{To cite this version:}

Mireille Jacquemond, Hervé Lot. L'ARN satellite du virus de la mosaïque du concombre. III. La propriété de survie in vivo. Agronomie, 1982, 2 (6), pp.533-538. 10.1051/agro:19820605 . hal02728342

\section{HAL Id: hal-02728342 \\ https://hal.inrae.fr/hal-02728342}

Submitted on 2 Jun 2020

HAL is a multi-disciplinary open access archive for the deposit and dissemination of scientific research documents, whether they are published or not. The documents may come from teaching and research institutions in France or abroad, or from public or private research centers.
L'archive ouverte pluridisciplinaire HAL, est destinée au dépôt et à la diffusion de documents scientifiques de niveau recherche, publiés ou non, émanant des établissements d'enseignement et de recherche français ou étrangers, des laboratoires publics ou privés. 


\title{
L'ARN satellite du virus de la mosaïque du concombre III. - La propriété de survie in vivo
}

\author{
Mireille JACQUEMOND \& Hervé LOT \\ avec la collaboration technique de Jean-Paul LEROUX \\ I.N.R.A., Station de Pathologie végétale, Centre de Recherches d'Avignon, F 84140 Montfavet.
}

\section{RÉSUMÉ}

Virus de la mosaïque du concombre.

Tomate,

Migration,

ARN satellite,

Survie.
L'ARN satellite du VMC (ARN-5) est retrouvé, biologiquement actif, plusieurs jours après son apport à une plante. Il ne s'accumule pas dans l'organe où il avait été apporté et ne migre pas à partir de cet organe. Cette propriété de survie a été établie selon deux méthodes:

1) Mise en évidence de l'ARN satellite dans un broyat de feuilles où il avait été antérieurement apporté ; 2) Inoculations, sur des feuilles d'étages différents d'une tomate, de l'ARN satellite et du génome viral. Cette dernière étude a été précédée par celle du mouvement, dans la tomate, du virus inoculé à un étage donné et donc, de la durée requise pour que les particules soient activement synthétisées dans les diverses parties de la plante.

Les ARN-5 de type D (responsables du développement du syndrome nécrotique létal de la tomate) et de type $\mathbf{R}$ (inducteurs de la réduction des symptômes dus à l'infection par le génome viral chez cet hôte) présentent la même aptitude à survivre in vivo.

La durée de survie de l'ARN-5 est de l'ordre de $25 \mathrm{j}$ chez la tomate, $15 \mathrm{j}$ chez le tabac et le concombre.

\section{SUMMARY}

Cucumber mosaic virus, Tomato,

Migration,

Satellite RNA

Survival.
Cucumber mosaic virus associated RNA-5. III. - Survival in vivo

The satellite RNA of CMV (RNA-5) keeps its biological activity several days after inoculation into leaves of a plant. Under these conditions, it does not accumulate in the inoculated organ and it does not migrate from this organ. This property of survival has been demonstrated by two methods:

1) recovery of the satellite RNA in crude sap from inoculated leaves;

2) inoculation of different leaves of a tomato plant with satellite RNA in the presence of helper virus. A check was first made of the movement, within the tomato, of the virus inoculated into a given leaf, and then, of the time required for the particles to be actively synthesized in the various parts of the plant.

RNA-5 of D type (causing tomato lethal necrosis) and of $R$ type (reducing the symptoms induced in tomato by the helper virus) have the same capacity to survive in vivo.

RNA-5 can survive for at least 25 days in tomato, or for 15 days in tobacco and cucumber.

\section{INTRODUCTION}

L'ARN satellite du virus de la mosaique du concombre est totalement dépendant, pour sa réplication, des ARN génomiques viraux. KAPER et al. (1976) ont effectivement montré qu'il n'est pas retrouvé parmi les ARN totaux isolés de plantes où il avait été apporté en l'absence du génome viral.

Les ARN-5 isolés de différentes souches de virus présentent des structures primaires similaires (KAPER \& TOUSIGNANT, 1978 ; RICHARDS et al., 1978). Ils possèdent également de nombreuses propriétés biologiques communes. Dotés d'une remarquable activité biologique - des traces d'ARN satellite dans un inoculum suffisent pour que sa réplication soit assurée - assistés par les ARN génomiques de souches homologues ou hétérologues, les ARN-5, en se multipliant, provoquent une importante réduction de la synthèse virale et des symptômes induits chez les hôtes du virus (WATERWORTH et al., 1979; JACOUEMOND \& LEROUX, 1982).

Un hôte, la tomate, permet de mettre en évidence une fonction biologique particulière qui n'est pas commune aux ARN satellites de toutes les souches de VMC. En effet, les ARN-5 de type D sont responsables du développement d'un syndrome nouveau chez cet hôte - la nécrose létale lorsqu'ils sont associés au virus. Par contre, les ARN-5 de type $\mathrm{R}$ induisent une réduction nette des symptômes de filiformisme dus à l'infection par le génome viral (JACQUEMOND \& LOT, 1981).

Des essais destinés à étudier l'éventualité de la multiplication et de la migration de l'ARN-5 « inoculé " isolément ont permis de démontrer sa capacité à survivre plusieurs jours après son apport à différentes espèces végétales. La propriété de survie a été antérieurement décrite par Mossop \& FRANCKI (1978) dans le cas de l'ARN satellite de souches australiennes de VMC, ou SAT-RNA. Cette démonstration 
a été faite par des expériences utilisant l'hybridation de l'ARN satellite et de son ADN complémentaire. Par des expérimentations de type biologique, nous confirmons cette aptitude particulière et présentons quelques facteurs qui interviennent sur son expression. En particulier, nous démontrons que l'ARN satellite de la souche R est, comme les ARN satellites nécrogènes de type $D$, capable de se maintenir actif in vivo.

\section{MATÉRIEL ET MÉTHODES}

\section{A. Les souches de virus}

Les caractéristiques des souches $\mathrm{I}_{17} \mathrm{~F}$ et $\mathrm{I}_{17} \mathrm{~N}$ - respectivement inductrices chez la tomate (Lycopersicon esculentum Mill.) de mosaïque filiforme et de nécrose - et des ARN satellites isolés des souches $\mathrm{D}, \mathrm{S}$ et $\mathrm{R}$, ainsi que les méthodes de purification et d'analyse en gel de polyacrylamide des ARN ont été décrites précédemment (JACQUEMOND \& LOT, 1981).

\section{B. Détection de l'ARN-5 dans un extrait de feuilles}

L'ARN-5 purifié est dilué, jusqu'à des concentrations qui seront précisées pour chaque essai, dans une solution saline phosphate disodique $0,03 \mathrm{M}, \mathrm{pH} 8,3$, et apporté sur les feuilles adultes des plantes en présence de carborandum (400 mesh, $75 \mathrm{mg} / \mathrm{ml}$ ). Ces plantes sont ensuite maintenues dans un compartiment de serre où la température est régulée approximativement $\left(14-16^{\circ} \mathrm{C}\right.$ durant la nuit, 24$27^{\circ} \mathrm{C}$ durant le jour) ou dans une enceinte climatique dont les caractéristiques sont : $16^{\circ} \mathrm{C}$ durant $10 \mathrm{~h}$ de nuit, $21^{\circ} \mathrm{C}$ durant $14 \mathrm{~h}$ de jour (4500 Lux), 70 p. 100 d'hygrométrie.

L'activité de l'ARN-5 de type $\mathrm{D}$ dans les feuilles où il a été apporté plusieurs jours auparavant est mise en évidence en inoculant de jeunes tomates ( 15 à $18 \mathrm{j}$ ) avec un extrait de ces feuilles dilué au $1 / 10$ dans une solution phosphate disodique $0,03 \mathrm{M}, \mathrm{pH} 8,3$ DIECA 2 p. 1000 et additionné des ARN de la souche $\mathrm{I}_{17} \mathrm{~F}(20 \mu \mathrm{g} / \mathrm{ml})$. L'apparition de cas de nécrose 15 à $20 \mathrm{j}$ après la contamination par ce mélange révèle en effet la présence de l'ARN satellite dans l'extrait des feuilles. L'inoculum témoin est constitué par les ARN de la souche $\mathrm{I}_{17} \mathrm{~F}$ dilués dans un broyat de feuilles ayant subi un simulacre d'infection par la solution saline.
La détection de l'ARN-5 de la souche $\mathrm{R}$, dépourvu d'activité nécrosante, se fait par analyse du contenu nucléique des particules synthétisées chez des tomates inoculées comme précédemment par le mélange constitué de l'extrait des feuilles du végétal ayant reçu l'ARN-5 et des ARN du virus assistant.

\section{Etude du mouvement du virus dans la tomate}

Les $A R N$ des souches $I_{17} F$ et $I_{17} N$ sont inoculés aux doses respectives de 20 et $40 \mu \mathrm{g} / \mathrm{ml}$ (la souche $I_{17} N$ contenant 45 p. 100 environ d'ARN satellite) à des tomates âgées de 22 à $25 \mathrm{j}$ (4 feuilles développées) sur la feuille immédiatement supérieure aux cotylédons (appelée feuille $n^{\circ} 1$, selon l'ordre d'apparition sur la tige).

Après l'infection, le virus est recherché chaque jour dans les diverses parties de 5 plantes, par indexage sur un hôte hypersensible, Vigna sinensis (L.) Endl. Les lésions locales nécrotiques développées sont dénombrées $48 \mathrm{~h}$ après l'inoculation. L'essai a été réalisé 3 fois dans les conditions de la serre.

\section{RÉSULTATS}

\section{A. Activité inhibitrice d'extraits de feuilles}

Un essai préliminaire a été réalisé afin de préciser le pouvoir inhibiteur d'extraits de feuilles sur les ARN génomiques et sur l'ARN satellite apporté à très faible concentration. Pour cela, les ARN de la souche $I_{17} F(20 \mu \mathrm{g} / \mathrm{ml})$ et l'ARN-5 de la souche $I_{17} \mathrm{~N} \quad\left(5 \times 10^{-4} \mu \mathrm{g} / \mathrm{ml}\right.$ ou $\left.5 \times 10^{-6} \mu \mathrm{g} / \mathrm{ml}\right)$ ont été ajoutés extemporanément à plusieurs dilutions d'un extrait de feuilles de tabac (Nicotiana tabacum L. cv. Xanthi nc.).

Les résultats présentés dans le tableau 1 montrent que la concentration utilisée pour les ARN génomiques est suffisante pour que l'infection soit initiée, quelle que soit la dilution de l'extrait végétal. La comparaison des taux de nécrose développée par les tomates ainsi contaminées fait néanmoins apparaître le pouvoir inhibiteur de l'extrait concentré. L'ARN-5, bien que présent en concentration faible dans l'inoculum, peut toutefois être détecté lorsqu'il a été apporté dans un broyat de feuilles réalisé au 1/10. Nous avons donc gardé ce facteur de dilution dans tous nos essais.

\section{TABLEAU 1}

Influence des inhibiteurs contenus dans un extrait de feuilles de tabacs sur la mise en évidence de l'ARN satellite présent en concentration faible dans l'inoculum.

Effect of tobacco leaf sap inhibitors on the detection of satellite RNA present in very low quantity in the inoculum.

\begin{tabular}{|c|c|c|c|}
\hline $\begin{array}{l}\text { Concentration de } \\
\text { l'ARN-5 dans } \\
\text { l'inoculum }\left(^{\text {a }}\right) \\
\quad(\mu \mathrm{g} / \mathrm{ml})\end{array}$ & \multicolumn{3}{|c|}{$\begin{array}{l}\text { p. } 100 \text { de nécrose }\left({ }^{b}\right) \text { obtenu parmi des tomates infectées } \\
\text { par les inoculums préparés dans: }\end{array}$} \\
\hline $\begin{array}{l}5 \times 10^{-4} \\
5 \times 10^{-6}\end{array}$ & $\begin{array}{r}100 \\
30\end{array}$ & $\begin{array}{l}30 \\
10\end{array}$ & $\begin{array}{l}90 \\
20\end{array}$ \\
\hline \multicolumn{4}{|c|}{$\begin{array}{l}\left({ }^{\text {a) }} \text { ARN de la souche } \mathrm{I}_{17} \mathrm{~F}(20 \mu \mathrm{g} / \mathrm{ml}) \text {. (Inocula contained } 20 \mu \mathrm{g} / \mathrm{ml} \mathrm{I}_{17} \mathrm{~F} \text { RNA). }\right. \\
\left({ }^{b}\right) \text { Les tomates non nécrosées ont développé les symptômes de mosaïque et filiformisme grave. (Non-necrosed tomato plants showed mosaic } \\
\text { and severe fern-leaf symptoms). } \\
\text { (c) } 1 \mathrm{~g} \text { de fcuilles pour } 9 \mathrm{ml} \text { de solution phosphate } 0,03 \mathrm{M} \mathrm{pH} 8,3 \text {. (1 } \mathrm{g} \text { of leaves per } 9 \mathrm{ml} \text { of } 0.03 \mathrm{M} \text { phosphate pH } 8.3 \text { ). }\end{array}$} \\
\hline
\end{tabular}


TABLEAU 2

Mise en évidence du maintien de l'activité biologique de l'ARN satellite inoculé à des tomates.

Survival of satellite RNA in tomato plants.

Durée d'incubation $\left({ }^{a}\right)$ (jours)

p. 100 de nécrose $\left(^{b}\right)$

1) Tomates maintenues en serre

$\begin{array}{rr}1 & 100 \\ 2 & 100 \\ 5 & 100 \\ 8 & 100 \\ 12 & 30\end{array}$

2) Tomates maintenues en enceinte climatique

$\begin{array}{rr}4 & 100 \\ 10 & 100 \\ 15 & 100 \\ 18 & 100 \\ 25 & 90 \\ 30 & 10\end{array}$

(a) Intervalle entre l'apport d'ARN satellite $\mathrm{I}_{17} \mathrm{~N}(20 \mu \mathrm{g} / \mathrm{ml})$ dans les feuilles de tomates et sa recherche dans les extraits de ces feuilles. (Interval between the inoculation of $\mathrm{I}_{17} \mathrm{~N}$ satellite RNA $(20 \mu \mathrm{g} / \mathrm{ml})$ into leaves of tomato plants and the test for its presence in the sap from these leaves).

(b) p. 100 de nécrose développée par les tomates inoculées par un extrait constitué de la souche $\mathrm{I}_{17} \mathrm{~F}$ (ARN, $\left.20 \mu \mathrm{g} / \mathrm{ml}\right)$ et du jus de feuilles de tomates ayant reçu une application d'ARN-5 et diversement incubées. Les tomates contaminées par les inoculums témoins ont extériorisé essentiellement les symptômes de mosaïque et filiformisme. (Per cent necrosis in tomato plants inoculated with a mixture of the helper genome $\left(\mathrm{I}_{17} \mathrm{~F}\right.$ RNA, $\left.20 \mu \mathrm{g} / \mathrm{ml}\right)$ and sap from leaves of tomato plants treated with satellite RNA and variously incubated. Control plants only displayed mosaic and fern-leaf symptoms).

\section{B. Mise en évidence de la propriété de survie}

\section{Maintien de l'activité de l'ARN-5 dans les feuilles de tomates}

Des tomates inoculées par friction d'un extrait constitué par l'addition des ARN purifiés $\mathrm{I}_{17} \mathrm{~F}$ à un broyat de feuilles de tomates inoculées depuis $8 \mathrm{j}$ par l'ARN-5 de type D (souche $\mathrm{I}_{17} \mathrm{~N}$ ) et maintenues dans les conditions de la serre, extériorisent essentiellement le syndrome nécrotique (tabl. 2). Le développement de ces symptômes prouve la présence d'ARN-5 biologiquement actif dans l'extrait végétal. Lorsque la durée d'incubation est portée à $12 \mathrm{j}$, l'ARN-5 est encore détecté dans l'extrait correspondant mais seulement 30 p. 100 des tomates se nécrosent.

Lorsque les tomates inoculées par l'ARN-5 sont maintenues en chambre climatisée, l'ARN-5 est retrouvé fonctionnel, dans un extrait de leurs feuilles, $25 \mathrm{j}$ après son apport.

\section{Inoculations du génome viral et de l'ARN-5 sur des feuilles d'étages différents}

Le résultat précédent suggère que l'ARN-5, apporté à une feuille de tomate, peut rester fonctionnel jusqu'à la migration et la réplication, à ce niveau, du virus assistant inoculé à un autre étage de la plante. Si cela est vrai, la tomate extériorisera le syndrome nécrotique. Par contre, si la durée requise pour que le virus soit activement répliqué dans les cellules où l'ARN satellite est présent est trop élevée, la plante développera les symptômes de filiformisme, révélateurs de l'absence d'ARN-5 fonctionnel. Pour préciser la durée du maintien en activité de l'ARN satellite, nous avons au préalable étudié le mouvement du virus dans la tomate.

\section{a) Mouvement du virus dans la tomate}

La progression, dans la tomate, du virus (souche $\mathrm{I}_{17} \mathrm{~F}$ ou $I_{17} N$ ) inoculé sur la feuille $n^{\circ} 1$, est représentée dans le tableau 3. Trois jours après l'infection, le virus n'est retrouvé que dans les folioles de la feuille inoculée et, occasionnellement, dans les racines secondaires. Le virus est ensuite rapidement synthétisé dans tous les organes de la plante puisqu'il y est détecté $6 \mathrm{j}$ après l'inoculation, exception faite de la feuille $n^{\circ} 2$ et des cotylédons. Toutefois, les concentrations de virus, estimées d'après les nombres de lésions locales développées sur les feuilles de $V$. sinensis, varient selon les parties considérées. En particulier, aux $5^{\text {e }}$ et $6^{\mathrm{e}}$ jours, le virus est très abondant dans la partie supérieure de la tige (à partir de la feuille $n^{\circ} 4$ ) et sa concentration est beaucoup plus faible dans la partie inférieure. Les dernières parties envahies sont les cotylé-

TABLEAU 3

Mouvement du VMC dans la tomate.

Movement of CMV within the tomato plant.

\begin{tabular}{|c|c|c|}
\hline $\begin{array}{l}\text { Jours après } \\
\left.\text { infection ( }{ }^{a}\right)\end{array}$ & $\begin{array}{c}\text { Stade de } \\
\text { développement }\left({ }^{b}\right)\end{array}$ & Parties de la plante où le virus est retrouvé $\left({ }^{c}\right)$ \\
\hline 0 & 4 & inoculation $\mathbf{F} 1\left(^{d}\right)$ \\
\hline 3 & 6 & folioles $\mathrm{F} 1$; parfois racines secondaires \\
\hline 4 & $6-7$ & $\mathrm{~F} 1,4,6,7$; système racinaire \\
\hline 5 & $7-8$ & $\mathrm{~F} 1,4,6,7,8$; folioles $\mathrm{F} 3,5$; tige entre $\mathrm{F} 4$ et $\mathrm{F} 8$; peu ou pas dans la partie inférieure \\
\hline 6 & 8 & $\mathrm{~F} 1,3,4,5,6,7,8 ;$ tige ; système racinaire \\
\hline 7 & $8-9$ & $\mathrm{~F} 1,3,4,5,6,7,8,9 ;$ tige ; système racinaire \\
\hline 13 & $10-\mathrm{BF} 1$ & $\mathrm{~F} 1,3,4,5,6,7,8,9,10, \mathrm{BF} 1$; cotylédons ; pétiole $\mathrm{F} 2$; tige ; système racinaire \\
\hline au-delà de 19 & & totalité de la plante exceptés, parfois, les folioles F 2 \\
\hline
\end{tabular}

(a) Inoculum constitué par les ARN des souches $I_{17} F(20 \mu \mathrm{g} / \mathrm{ml})$ ou $I_{17} \mathrm{~N}(40 \mu \mathrm{g} / \mathrm{ml})$. (Inocula contained $20 \mu \mathrm{g} / \mathrm{ml} \mathrm{I} \mathrm{I}_{17} \mathrm{~F} \mathrm{RNA}$ or $40 \mu \mathrm{g} / \mathrm{ml} \mathrm{I} \mathrm{I}_{17} \mathrm{~N}$ RNA).

( $\left.{ }^{b}\right)$ Nombre de feuilles développées, BF 1 : premier bouquet floral. (Number of leaves developed, BF $1:$ first inflorescence).

(c) Sont reportées toutes les parties de la plante où le virus a pu être détecté même s'il se trouvait en concentration très faible ainsi que l'indiquait le nombre de lésions formées sur les feuilles de $V$. sinensis. (All the parts of the plant where the virus was detected, are reported even if it was in very low concentration according to the number of local lesions developed on leaves of $V$. sinensis).

(d) F 1 : feuille $n^{\circ} 1$. (F 1 : leaf $n^{\circ} 1$ ). 
dons (minimum $13 \mathrm{j}$ après l'infection), s'ils persistent toujours, et la feuille $n^{\circ} 2$. Cette dernière n'est d'ailleurs pas toujours infectée. Au-delà des $15-16^{\mathrm{e}} \mathrm{j}$, la concentration du virus dans la partie basse de la tige et dans les feuilles les plus âgées $(1,2$ et 3 ) diminue progressivement.

b) Faciès de la maladie développée par des tomates inoculées sur des feuilles d'étages différents par le génome viral et l'ARN-5

Le développement de nécrose létale parmi les tomates inoculées par le génome viral sur la feuille $n^{\circ} 1$ et l'ARN-5 sur les feuilles $n^{\circ} 2,3,4$ ou sur les cotylédons, prouve que l'ARN satellite est toujours présent puisqu'il a pu être assisté par les ARN génomiques (tabl. 4). Compte tenu des délais requis pour que le virus soit répliqué dans les feuilles successives de la plante, il apparaît que l'ARN-5, s'il n'a pas migré à partir de la feuille où il avait été apporté, s'est maintenu biologiquement actif une vingtaine de jours.

\section{Contrôle de l'accumulation et de la migration de l'ARN-5}

Les résultats précédents suggèrent que l'ARN-5 peut subsister de longues périodes à l'état latent dans la feuille où il avait été apporté, ou bien qu'il peut se répliquer indépendamment des ARN du génome viral, ou encore qu'il peut migrer à partir de l'organe inoculé.

La réduction de la teneur de l'ARN satellite dans les extraits de feuilles - représentée dans les tableaux $2,5,6$, par la réduction des taux de tomates nécrosées - lorsque la durée d'incubation augmente, montre qu'il n'y a pas accumulation d'ARN-5 dans la feuille inoculée et qu'il n'est vraisemblablement pas capable de se répliquer de façon autonome.

La migration de l'ARN-5 à partir de la feuille où il a été apporté paraît peu probable. En effet, le développement de mosaïque filiforme par des tomates infectées par la souche $I_{17} F$ sur la feuille $n^{\circ} 1$ et l'ARN satellite sur la feuille $n^{\circ} 2$ feuille tardivement et sporadiquement infectée par le virus - tend à prouver l'absence de migration de l'ARN satellite. De plus, la recherche dans les feuilles $1,3,4$ et dans les racines de tomates où l'ARN-5 avait été apporté 4 et $8 \mathrm{j}$ auparavant sur la feuille $\mathrm{n}^{\circ} 1$, n'a permis de le détecter que dans cette feuille $n^{\circ} 1$

\section{Aptitude à la survie d'ARN-5 de provenances diffé- rentes}

La relation virus - ARN satellite ne présente pas de spécificité étroite. En particulier, les ARN-5 des souches D, $\mathrm{S}$ ou R peuvent, comme l'ARN-5 de la souche $\mathrm{I}_{17} \mathrm{~N}$, être assistés par le génome viral $\mathrm{I}_{17} \mathrm{~F}$ (JACQUEMOND \& LEROUX, 1982). L'aptitude à survivre de ces 4 ARN satellites a été éprouvée chez le tabac maintenu en chambre climatisée. Elle est estimée par le pourcentage de nécrose développée par des tomates infectées par le mélange du génome $\mathrm{I}_{17} \mathrm{~F}$ et de l'extrait de feuilles de tabacs ayant reçu l'application de l'ARN-5, dans le cas des ARN satellites $I_{17} N$, D ou S, et par la proportion relative d'ARN-5 dans les particules synthétisées chez les tomates infectées selon le même protocole dans le cas de l'ARN satellite $R$ (tabl. 5). Ces résultats montrent que les $4 \mathrm{ARN}$ satellites survivent durant des périodes comparables, de l'ordre de 15 jours, chez le tabac. En particulier, des taux de nécrose similaires sont obtenus avec les inoculums correspondant aux broyats de feuilles ayant reçu les $A R N-5 I_{17} N$ ou $S$.

\section{Comparaison de l'aptitude de 3 hôtes du VMC à assurer la survie de l'ARN-5}

Contrairement au concombre (Cucumis sativus L. cv. "Vert Long Maraîcher »), la tomate et le tabac sont particulièrement favorables à la synthèse de l'ARN satellite qui peut représenter 45 à 50 p. 100 du contenu nucléique des particules (JACQUEMOND \& LEROUX, 1982). Ces hôtes ont donc été choisis pour éprouver l'aptitude de l'ARN-5 (souche $\mathrm{I}_{17} \mathrm{~N}$ ) à survivre chez différentes espèces végétales.

Comme le montrent les résultats présentés dans le tableau 6, la durée de survie de l'ARN-5 dépend étroitement des espèces sur les feuilles desquelles il a été appliqué. Elle est supérieure à $25 \mathrm{j}$ chez la tomate et de l'ordre de $15 \mathrm{j}$ chez le tabac et le concombre, les plantes étant maintenues en enceinte climatique durant leur incubation. (Il semblerait qu'il n'existe pas de relation entre les aptitudes de ces hôtes à assurer la réplication ou la survie de l'ARN satellite.)

TABLEAU 4

Proportion de tomates atteintes de nécrose après les inoculations simultanées du génome viral sur la feuille $n^{o} 1$ et de l'ARN satellite sur des feuilles d'étages différents.

Proportion of tomato plants showing lethal necrosis after infection with helper genome on the first leaf and satellite RNA on the others.

p. 100 de nécrose $\left({ }^{a}\right)$ obtenu parmi les tomates $\left({ }^{b}\right)$ lorsque

l'ARN satellite (c) est apporté sur :

Exp.

Cotylédons $\quad$ Feuille $n^{\circ} 2 \quad$ Feuille $n^{\circ} 3 \quad$ Feuille $n^{\circ} 4$

\begin{tabular}{|c|c|c|c|c|c|}
\hline 1 & 0 & - & 50 & 100 & 100 \\
\hline 2 & 0 & 70 & 90 & 100 & 100 \\
\hline 3 & 0 & 50 & 60 & 100 & 100 \\
\hline 4 & 0 & 40 & - & - & - \\
\hline
\end{tabular}

( $\left.{ }^{a}\right)$ Les plantes non nécrosées ont extériorisé les symptômes de mosaïque et filiformisme grave. (Non-necrosed tomato plants showed mosaic and severe fern-leaf symptoms).

$\left.{ }^{b}\right)$ Toutes les plantes sont au stade 4 feuilles lors de l'inoculation. (All plants were at the $4^{\text {th }}$ leaf-stage when inoculated).

(c) ARN-5 I ${ }_{17} \mathrm{~N}, 20 \mu \mathrm{g} / \mathrm{ml}$. $\left(20 \mu \mathrm{g} / \mathrm{ml} \mathrm{I} I_{17} \mathrm{~N}\right.$ RNA-5). 
TABLEAU 5

Comparaison de l'aptitude à survivre chez le tabac d'ARN-5 $\left(^{a}\right)$ de provenances différentes. Survival capacity, on tobacco plants, of RNA-5 isolated from different CMV strains.

\begin{tabular}{|c|c|c|c|c|c|}
\hline \multirow{2}{*}{$\begin{array}{c}\text { Durée d'incubation } \\
\text { (jours) }\end{array}$} & \multicolumn{3}{|c|}{$\begin{array}{l}\text { Détection des ARN-5 de type } D\left({ }^{b}\right) \\
\text { p. } 100 \text { de nécrose }\end{array}$} & \multicolumn{2}{|c|}{ Détection de l'ARN-5 R (c) } \\
\hline & ARN-5 $I_{17} \mathrm{~N}$ & ARN-5 D & ARN-5 S & $\begin{array}{l}\text { Rendement virus } \\
\text { (mg/kg) }\end{array}$ & $\begin{array}{l}\text { p. } 100 \\
\text { ARN-5 }\end{array}$ \\
\hline $\begin{array}{r}4 \\
8 \\
11 \\
15\end{array}$ & $\begin{array}{l}97,5 \\
82,2 \\
67,5 \\
34,2\end{array}$ & $\begin{array}{l}82,5 \\
62,0 \\
47,5 \\
13,1\end{array}$ & $\begin{array}{l}90,0 \\
72,5 \\
50,0 \\
40,0\end{array}$ & $\begin{array}{l}218,7 \\
412,2 \\
387,5 \\
898,8\end{array}$ & $\begin{array}{r}34,5 \\
10,1 \\
14,8 \\
0,9\end{array}$ \\
\hline Inoculum témoin & & 0 & & 1311,8 & 0 \\
\hline \multicolumn{6}{|c|}{$\begin{array}{l}\left({ }^{a}\right) \text { Les ARN-5 ont été apportés à la dose de } 10 \mu \mathrm{g} / \mathrm{ml} \text {. Les tabacs ont été maintenus en enceinte climatique durant leur incubation. Les valeurs } \\
\text { indiquées correspondent aux moyennes établies pour trois essais successifs. } \\
\text { (RNA-5 was inoculated at } 10 \mu \mathrm{g} / \mathrm{ml} \text {. Tobacco plants were incubated in a growth cabinet. The results correspond to the mean values obtained } \\
\text { for } 3 \text { experiments.) } \\
\text { (b) p. } 100 \text { de tomates nécrosées après leur inoculation par les extraits mêlant les ARN } \mathrm{I}_{17} \mathrm{~F}(20 \mu \mathrm{g} / \mathrm{ml}) \text { avec les broyats de feuilles (tabacs) ayant } \\
\text { reçu une application d'ARN-5 et diversement incubées. } \\
\text { (Per cent of necrosed tomato plants after inoculation with a mixture of helper genome }\left(\mathrm{I}_{17} \mathrm{~F} \mathrm{RNA}, 20 \mu \mathrm{g} / \mathrm{ml}\right) \text { and crude sap from tobacco leaves } \\
\text { previously inoculated with RNA-5.) } \\
\left.\text { (c) L'ARN-5 est mis en évidence dans les nucléoprotéines purifiées à partir des tomates inoculées comme décrit dans ( }{ }^{\mathrm{a}}\right) \text {. (RNA-5 detected in } \\
\text { the nucleoproteins recovered from the tomato plants inoculated as described in }\left({ }^{\mathrm{a}}\right) \text { ). }\end{array}$} \\
\hline
\end{tabular}

\section{TABLEAU 6}

Comparaison de l'aptitude de 3 espèces hôtes à assurer la survie de l'ARN-5 $\left({ }^{a}\right)$.

Comparison of the aptitude of 3 host species to ensure the survival of RNA-5.

\begin{tabular}{|c|c|c|c|c|}
\hline \multirow[t]{2}{*}{ Exp. } & \multirow[t]{2}{*}{$\begin{array}{l}\text { Nombre de jours } \\
\text { après l'application } \\
\text { de l'ARN-5 }\end{array}$} & \multicolumn{3}{|c|}{$\begin{array}{l}\text { P. } 100 \text { de nécrose observée parmi les tomates } \\
\text { infectées au moyen d'inoculums constitués par les } \\
\text { extraits de feuilles où l'ARN-5 a été antérieu- } \\
\text { rement appliqué, additionnés des ARN } I_{17} F\end{array}$} \\
\hline & & Tomate & Tabac & Concombre \\
\hline \multirow[t]{5}{*}{1} & 6 & 100 & 100 & 80 \\
\hline & 8 & 100 & 80 & 70 \\
\hline & 10 & 100 & 90 & 70 \\
\hline & 15 & 90 & 30 & 40 \\
\hline & 20 & 60 & 20 & - \\
\hline \multirow[t]{6}{*}{2} & 5 & 100 & 100 & 80 \\
\hline & 10 & 100 & 100 & 80 \\
\hline & 14 & 100 & 30 & 20 \\
\hline & 20 & 100 & 10 & 10 \\
\hline & 25 & 50 & 0 & 0 \\
\hline & 31 & 10 & - & - \\
\hline
\end{tabular}

(a) L'ARN-5 de la souche $I_{17} N$ a été apporté à la dose de $10 \mu \mathrm{g} / \mathrm{ml}$; les plantes ont été maintenues en enceinte climatique durant leur incubation. Les tomates non nécrosées et les tomates des lots témoins ont développé les symptômes de mosaique et filiformisme grave. $\left(\mathrm{I}_{17} \mathrm{~N}\right.$ RNA-5 was inoculated at $10 \mu \mathrm{g} / \mathrm{ml}$; the plants were kept in a growth cabinet during incubation. Non-necrosed tomato plants and controls developed mosaic and severe fern-leaf symptoms.)

\section{DISCUSSION}

L'ARN satellite du VMC possède la propriété de préserver ses fonctions biologiques et, probablement, l'intégrité de sa structure, durant des périodes variables après avoir été inoculé à une plante. L'absence apparente de réplication autonome de l'ARN-5 apporté sans les ARN du génome et l'absence de migration à partir de l'organe inoculé confirment qu'il s'agit d'une propriété de survie. Cette propriété, commune aux ARN-5 de type $\mathrm{D}$ et $\mathrm{R}$, n'est pas spécifique à un hôte donné puisqu'elle a été établie chez différentes espèces végétales. 
L'étude comparée de la capacité de l'ARN-5 à survivre chez des plantes maintenues en serre ou en enceinte climatique a montré le rôle déterminant des conditions d'incubation sur la durée de survie. Notamment, l'ARN-5 ne reste fonctionnel que 8 à $12 \mathrm{j}$ chez les tomates maintenues en serre alors que la période de survie atteint $25 \mathrm{j}$ lorsque les plantes sont maintenues en enceinte climatique (tabl. 2). De plus, des résultats constants ont été obtenus au cours de plusieurs essais réalisés en chambre climatisée alors qu'ils varient avec la période de l'année lorsque les essais sont conduits en serre (résultats non présentés).

KASSANIS, en 1966, avait suggéré que le satellite du virus de la nécrose du tabac (SV-TNV) pouvait survivre, in vivo. Ce satellite, encapsidé dans sa propre protéine, est dépendant, pour sa réplication, du génome viral. Cette propriété du SV-TNV a été confirmée par MossOP \& FRANCKI (1979a) et également établie pour l'ARN satellite de souches australiennes de VMC (SAT-RNA) par ces mêmes auteurs (1978). Comme l'ARN-5 de type R, le SAT-RNA induit une nette réduction des symptômes viraux chez la tomate, mais il ne présente que 70 p. 100 d'homologies de séquence avec l'ARN-5 (MOSSOP \& FRANCKI, 1979b). La capacité de survivre in vivo constitue donc une autre propriété commune aux divers ARN satellites du VMC décrits.

Le mode de conservation de l'ARN satellite apporté isolément à une plante n'a pas été établi. La détection de l'ARN-5 dans un extrait de feuilles où il avait été apporté antérieurement peut signifier que l'ARN-5 est resté en surface de la feuille ou bien qu'il y a pénétré. Cette deuxième possibilité peut être retenue puisque l'ARN-5, apporté sur la feuille d'une tomate à un certain étage, peut être assisté par le virus provenant d'un étage différent de la plante. La faculté de survivre suggère une résistance particulière de cette molécule. Le SAT-RNA ou l'ARN-5 sont effectivement plus stables, in vitro, que les ARN du génome (MOSSOP \& FRANCKI, 1979a; JACQUEMOND, 1980). Il est également possible que l'ARN satellite soit partiellement protégé grâce à des interactions avec la cellule envahie. Néanmoins, l'ARN-5 est progressivement dégradé. Sa concentration dans des extraits de feuilles de tabacs où il avait été apporté $15 \mathrm{j}$ auparavant doit être extrêmement faible compte tenu des résultats énoncés dans le tableau 4. En effet, lorsqu'il est présent à la dose de $5 \times 10^{-4} \mu \mathrm{g} / \mathrm{ml}$ dans l'inoculum, l'ARN-5 représente 45 p. 100 environ du contenu nucléique des particules synthétisées chez la tomate et provoque, lorsqu'il est du type $\mathrm{D}$, la nécrose de la totalité des tomates infectées. Par contre, lorsqu'il est présent en concentration encore plus faible, sa synthèse devient aléatoire ; il représente une proportion très faible de l'ARN total synthétisé et le pourcentage de tomate se nécrosant est réduit (JACQUEMOND \& LEROUX, 1982). Cela semble être le cas de l'inoculum correspondant à des feuilles de tabacs inoculées depuis $15 \mathrm{j}$ par les ARN-5 de type D ou R.

L'aptitude à survivre que possèdent les ARN-5, associée à l'absence de spécificité de la relation virus - ARN satellite, constitue une donnée nouvelle particulièrement intéressante d'un point de vue épidémiologique. Elle pourrait intervenir dans 2 situations :

- le génome viral, transmis par les pucerons, vecteurs naturels du virus, n'est pas en concentration suffisante pour initier l'infection. L'ARN-5, simultanément transmis, pourra être assisté par le virus apporté au cours d'une infection ultérieure;

- 2 groupes de souches de VMC, définis selon des critères de thermosensibilité (MARCHOUX et al., 1976), peuvent se succéder sur une même plante dans les conditions naturelles d'infection, lorsque certains facteurs, telle la température, y sont favorables (DouINE et al., 1979). Cette succession serait le fait de recontaminations. L'ARN-5 pourrait être intégré dans les particules de la souche surinfectante.

Reçu le 26 octobre 1981 Accepté le 17 février 1982

\section{RÉFÉRENCES BIBLIOGRAPHIQUES}

Douine L., Marchoux G., Quiot J. B., Clément M., 1979. Phénomènes d'interférences entre souches du virus de la mosaïque du concombre (CMV). II. Effet de la température d'incubation sur la multiplication de deux souches de sensibilités thermiques différentes, inoculées simultanément ou successivement à un hôte sensible Nicotiana tabacum var. Xanthi nc. Ann. Phytopathol., 11 (3), 421 430 .

Jacquemond M., 1980. Propriétés et fonctions biologiques du satel lite du virus de la mosaique du concombre. La nécrose de la tomate. Thèse de Docteur Ingénieur, Université d'Aix-Marseille, 167 pp.

Jacquemond M., Leroux J. P., 1982. L'ARN satellite du virus de la mosaïque du concombre. II. Etude de la relation virus - ARN satellite chez divers hôtes. Agronomie, 2 (1), 55-62.

Jacquemond M., Lot H., 1981. L'ARN satellite du virus de la mosaïque du concombre. I. Comparaison de l'aptitude à induire la nécrose de la tomate d'ARN satellites isolés de plusieurs souches de virus. Agronomie, 1 (10), 927-932.

Kaper J. M., Tousignant M. E., 1978. Cucumber mosaic virus associated RNA-5. V. Extensive nucleotide sequence homology among CARNA-5 preparations of different CMV strains. Virology, 85, 323-327

Kaper J. M., Tousignant M. E., Lot H., 1976. A low molecular weight replicating RNA associated with a divided genome plant virus : defective or satellite RNA? Biochem. Biophys. Res. Comm., 72 (4), 1237-1243.

Kassanis B., 1966. Properties and behaviour of satellite viruses, p. 177-187. In Beemster A. B. R. and Dijkstra J. Viruses of plants, North Holland publ, Amsterdam.

Marchoux G., Douine L, Quiot J. B., 1976. Comportement thermique différentiel de certaines souches du VMC. Hypothèse d'un mécanisme pléiotropique reliant plusieurs propriétés. C.R. Acad. Sci. Paris, sér. D, 283, 1601-1604.

Mossop D. W., Francki R. I. B., 1978. Survival of a satellite RNA in vivo and its dependence on cucumber mosaic virus for replication. Virology, 86, 562-566.

Mossop D. W., Francki R. I. B., 1979a. Stability of satellite RNAs in vivo and in vitro. Virology, 94, 243-253.

Mossop D.W., Francki R. I. B., 1979b. Comparative studies on two satellite RNAs of cucumber mosaic virus. Virology, 95, 395404.

Richards K. E., Jonard G., Jacquemond M., Lot H., 1978. Nucleotide sequence of cucumber mosaic virus associated RNA-5. Virology, 89, 395-408.

Waterworth H. E., $\quad$ Kaper J. M., $\quad$ Tousignant M. E., 1979. CARNA-5, the small cucumber mosaic virus-dependent replicating RNA, regulates disease expression. Science, 204, 845-847. 